\title{
Necessity of a Standardized Reporting System of Antiphospholipid Antibody Tests: Relevance for COVID-19
}

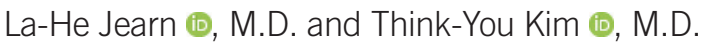 \\ Division of Diagnostic Immunology, Department of Laboratory Medicine, College of Medicine, Hanyang University, Seoul, Korea
}

\section{Dear Editor,}

We had previously reported that rheumatoid factor is not a contributing factor to the risk of deep vein thrombosis and suggested that autoantibodies such as antiphospholipid antibodies (aPL) could be a possible trigger [1]. In the face of the recent coronavirus disease 2019 (COVID-19) pandemic, among various reports on its clinical features, we have been interested in emerging reports on associations between aPL and thromboembolic events in COVID-19 patients [2-6].

Despite the potential importance of $\mathrm{PPL}$ as a clue to the pathogenic mechanism of coagulopathy in COVID-19, these recent reports demonstrate a lack of expertise and no standardized reporting system (Table 1). Therefore, as laboratory physicians, we highlight five key problems associated with reporting aPL test results, with particular relevance to COVID-19.

First, there is a lack of reporting of the antibody titer. Transient elevation of aPL level may occur during infection; therefore, low titers of aPL have low clinical significance. Consequently, reporting the aPL level in numerical form is a very basic and important factor for diagnosing antiphospholipid antibody syndrome (APS), which is based on an anticardiolipin ( $\mathrm{aCL}$ ) level $>40$ lgG phospholipid (GPL)//gM phospholipid (MPL) or > 99th percentile (p99), or anti-beta-2-glycoprotein I (aß2GPI) > p99.
Second, there is a lack of reporting of the cut-off value for these tests. The solid-phase aPL test guidelines recommend using the p99 as a cut-off value for both aCL and aß2GPI tests [7]. However, not all reagents can reflect the p99. In particular, for aCL, GPL or MPL units $(\mathrm{U} / \mathrm{mL})$ are still used, and therefore the cutoff for many reagents remains inconsistent with the p99. Some manufacturers provide additional information on the GPL/MPL levels corresponding to the p99; however, $40 \mathrm{GPL} / \mathrm{MPL}$ is generally higher than the p99. Considering the variety of cut-off values, the setting condition and related information of the reagents should be carefully checked and presented in reports.

Overall, the p99 is more widely used, especially in new automated systems such as fluorescence enzyme immunoassay (FEIA) and chemiluminescence immunoassay (CLIA) than in conventional ELISA, and in aß2GPI test reagents than in aCL test reagents. However, in the field of obstetric medicine, the inclusion of low-titer aCL and aß2GPI for the diagnosis of purely obstetric APS has been continuously recommended; therefore, there are different views on the appropriate cut-off value with respect to the 95th or 97.5th percentile [8].

Third, the detailed methods and manufacturers of kits are often not mentioned in these reports. Various reagents are used for ELISA worldwide, which show corresponding variability; how-
Received: October 22, 2020

Revision received: December 15, 2020

Accepted: May 6, 2021

Corresponding author: Think-You Kim, M.D.

Division of Diagnostic Immunology, Department of Laboratory Medicine, College of Medicine, Hanyang University, 222 Wangsimni-ro, Seongdonggu, Seoul 04763, Korea

Tel: +82-2-2290-8978, Fax: +82-2-2290-9193

E-mail: tykim@hanyang.ac.kr 
Table 1. Recent reports on aPL associated with COVID-19

\begin{tabular}{|c|c|c|c|c|c|}
\hline Characteristics & $\begin{array}{l}\text { Zhang, } \\
\text { et al. } \\
2020 \text { [2] }\end{array}$ & $\begin{array}{c}\text { Harzallah, } \\
\text { et al. } \\
2020 \text { [3] }\end{array}$ & $\begin{array}{c}\text { Beyrouti, } \\
\text { et al. } \\
2020 \text { [4] }\end{array}$ & $\begin{array}{l}\text { Sung and } \\
\text { Anjum } \\
2020[5]\end{array}$ & $\begin{array}{c}\text { Hossri, } \\
\text { et al. } \\
2020 \text { [6] }\end{array}$ \\
\hline Cases (N) & 3 & 56 & 6 & 1 & 2 \\
\hline \multicolumn{6}{|l|}{$\mathrm{aCl}$} \\
\hline Titer & No & No & grade & Yes & Yes \\
\hline Cut-off value & No & No & No & Yes & Yes \\
\hline Methods & No & No & No & No & No \\
\hline Manufacturers & No & No & No & No & No \\
\hline IgA test & Yes & NT & NT & Yes & NT \\
\hline \multicolumn{6}{|l|}{$\mathrm{a} \beta 2 \mathrm{GPI}$} \\
\hline Titer & No & No & grade & Yes & No \\
\hline Cut-off value & No & No & No & Yes & No \\
\hline Methods & No & No & No & No & No \\
\hline Manufacturers & No & No & No & No & No \\
\hline IgA test & Yes & NT & NT & Yes & NT \\
\hline \multicolumn{6}{|l|}{$L A$} \\
\hline Methods & No & Yes & No & Yes & NT \\
\hline Manufacturers & No & No & No & No & NT \\
\hline Dually checked & No & Yes & No & Yes & NT \\
\hline $\begin{array}{l}\text { Dual test } \\
\text { interpretation }\end{array}$ & No & No & No & Yes & NT \\
\hline
\end{tabular}

Abbreviations: aPL, antiphospholipid antibodies; COVID-19, coronavirus disease 2019; aCL, anticardiolipin; NT, not tested; aß2GPI, anti-beta-2-glycoprotein I; LA, lupus anticoagulant.

ever, more recent automation systems such as FEIA and CLIA tend to reduce the variability. Moreover, CLIA is characterized by significantly improved background noise, which can be more sensitive than other methods. Therefore, information on the methodology and manufacturers is crucial for establishing a diagnosis of APS.

Fourth, there is a lack of clarity in the reports on IgA aPL. IgA is recommended for interpreting the clinical implications of aPL when both IgG and IgM tests are negative. However, the results of IgA tests are rarely reported, and there is insufficient data and lack of consensus of the clinical relevance. This issue should be handled with caution as a sensitive subject in case reports. Unlike IgG and IgM, IgA measurement cannot be calibrated; Thus, the basic information for the test described above is more essential.

Fifth, the possibility of a false-positive result for the lupus anticoagulant (LA) test is rarely considered. The challenge of securing an adequate sample is a more fundamental issue than standardizing the procedure in actual LA testing. In recent reports, highly frequent LA positivity of 45\% (25/56) and $83.3 \%$ (5/6) was found in COVID-19 patients without thromboembolism and in stroke patients, respectively [3, 4]. However, the possibility of false positives cannot be excluded due to a high C-reactive protein level or the anticoagulant drug dosed for coagulopathy management $[9,10]$. A false-positive LA result is more likely when compared to the positive result frequency of solid-phase aPL tests of only $10 \%(5 / 50)$ and $16.7 \%(1 / 6)$ in these two studies, respectively. Therefore, LA testing in an acute ill state is not recommended [10].

In closing, the substantial confusion caused by the COVID-19 pandemic can be likened to a Korean proverb: "No matter the urgency, you must thread through the eye of the needle not around the needle." That is, to obtain reliable results, the basics and principles of laboratory testing and reporting need to be followed and maintained under the current urgency of the pandemic more stringently than ever. In particular, the reporting of titers, cut-offs, test methods, manufacturers, and other detailed information can be used as a basic principle to reduce the confusion regarding inter-assay variability, allowing clinicians to obtain more accurate information on the condition of their patients. Checking for antibody persistence or verification using other methods is also recommended. The LA testing should not be considered in an acute ill state due to sample problem.

Standardization of aPL tests is an ongoing issue, with continuous efforts from various international committees to achieve a consensus. Thus, we hope that COVID-19 would be a trigger to find a resolution.

\section{AUTHOR CONTRIBUTIONS}

Kim TY developed the concept for this manuscript. Kim TY and Jearn LH wrote and reviewed the manuscript. Kim TY and Jearn $\mathrm{LH}$ read and approved the final manuscript.

\section{CONFLICTS OF INTEREST}

None declared.

\section{RESEARCH FUNDING}

None declared.

\section{ORCID}

La-He Jearn

https://orcid.org/0000-0002-6712-3895 


\section{Jearn LH, et al.}

Standardized reporting of aPL in COVID-19

Think-You Kim

$$
\text { https://orcid.org/0000-0002-4131-0107 }
$$

\section{REFERENCES}

1. Jearn LH and Kim TY. Is rheumatoid factor really associated with deep venous thrombosis? Clin Chem 2015;61:1546-7.

2. Zhang Y, Xiao M, Zhang S, Xia P, Cao W, Jiang W, et al. Coagulopathy and antiphospholipid antibodies in patients with Covid-19. N Engl J Med 2020;382:e38.

3. Harzallah I, Debliquis A, Drénou B. Lupus anticoagulant is frequent in patients with Covid-19. J Thromb Haemost 2020;18:2064-5.

4. Beyrouti R, Adams ME, Benjamin L, Cohen H, Farmer SF, Goh YY, et al. Characteristics of ischaemic stroke associated with COVID-19. J Neurol Neurosurg Psychiatry 2020;91:889-91.

5. Sung J and Anjum S. Coronavirus disease 2019 (COVID-19) infection associated with antiphospholipid antibodies and four-extremity deep vein thrombosis in a previously healthy female. Cureus 2020;12:e8408.
6. Hossri S, Shadi M, Hamarsha Z, Schneider R, El-Sayegh D. Clinically significant anticardiolipin antibodies associated with COVID-19. J Crit Care 2020;59:32-4.

7. Devreese KMJ, Ortel TL, Pengo V, de Laat B, Subcommittee on Lupus Anticoagulant/Antiphospholipid Antibodies. Laboratory criteria for antiphospholipid syndrome: communication from the SSC of the ISTH. J Thromb Haemost 2018;16:809-13.

8. Gardiner C, Hills J, Machin SJ, Cohen H. Diagnosis of antiphospholipid syndrome in routine clinical practice. Lupus 2013;22:18-25.

9. Schouwers SM, Delanghe JR, Devreese KM. Lupus anticoagulant (LAC) testing in patients with inflammatory status: does C-reactive protein interfere with LAC test results? Thromb Res 2010;125:102-4.

10. Pengo V, Tripodi A, Reber G, Rand JH, Ortel TL, Galli M, et al. Update of the guidelines for lupus anticoagulant detection. Subcommittee on Lupus Anticoagulant/Antiphospholipid Antibody of the Scientific and Standardisation Committee of the International Society on Thrombosis and Haemostasis. J Thromb Haemost 2009;7:1737-40. 